\title{
Atmospheric station Křešín u Pacova, Czech Republic - a Central European research infrastructure for studying greenhouse gases, aerosols and air quality
}

\author{
A. Dvorská ${ }^{1}$, P. Sedlák ${ }^{1,2}$, J. Schwarz ${ }^{3}$, M. Fusek ${ }^{4}$, V. Hanuš ${ }^{1}$, P. Vodička ${ }^{3}$, and J. Trusina ${ }^{1}$ \\ ${ }^{1}$ Global Change Research Centre, Czech Academy of Sciences, Brno, Czech Republic \\ ${ }^{2}$ Institute of Atmospheric Physics, Czech Academy of Sciences, Praha, Czech Republic \\ ${ }^{3}$ Institute of Chemical Process Fundamentals, Czech Academy of Sciences, Praha, Czech Republic \\ ${ }^{4}$ Brno University of Technology, Brno, Czech Republic \\ Correspondence to: A. Dvorská (dvorska.a@czechglobe.cz)
}

Received: 14 January 2015 - Revised: 8 April 2015 - Accepted: 25 April 2015 - Published: 6 May 2015

\begin{abstract}
Long-lasting research infrastructures covering the research areas of atmospheric chemistry, meteorology and climatology are of highest importance. The Atmospheric Station (AS) Křešín u Pacova, central Czech Republic, is focused on monitoring of the occurence and long-range transport of greenhouse gases, atmospheric aerosols, selected gaseous atmospheric pollutants and basic meteorological characteristics. The AS and its $250 \mathrm{~m}$ tall tower was built according to the recommendations of the Integrated Carbon Observation System (ICOS) and cooperates with numerous national and international projects and monitoring programmes. First measurements conducted at ground started in 2012, vertical profile measurements were added in 2013. A seasonal variability with slightly higher autumn and winter concentrations of elemental and organic carbon was revealed. The suitability of the doubly left-censored Weibull distribution for modelling and interpretation of elemental carbon concentrations, which are often lower than instrumental quantification limits, was verified. Initial data analysis also suggests that in summer, the tower top at $250 \mathrm{~m}$ is frequently above the nocturnal surface inversions, thus being decoupled from local influences.
\end{abstract}

\section{Introduction}

Masts, towers and other tall constructions are used for meteorological measurements and planetary boundary layer studies since the 19th century (Monna and Bosveld, 2013). In the 1990s, tall towers started to be used as part of the greenhouse gas (GHG) observational infrastructure. Currently, the ICOS (Integrated Carbon Observation System) infrastructure is being built in Europe and a network of tall towers forms a central element of this research and monitoring infrastructure. Tall towers allow to obtain atmospheric observations that are representative for a larger region because placement of measurements at higher altitudes above ground minimizes the influence of very local fluxes on the observations (Bakwin et al., 1998; Haszpra et al., 2012). Measurements at tall towers also overcome the problem of complicated airflow in the lowermost $100-200 \mathrm{~m}$ of the planetary boundary layer (Stull,
1988). The same benefit is obtained for measurements of atmospheric pollutants such as tropospheric ozone or aerosols at tall tower sites.

The Atmospheric Station (AS) Křešín u Pacova $\left(49^{\circ} 35^{\prime}\right.$ N, $15^{\circ} 05^{\prime} \mathrm{E}$ ) consists mainly of a $250 \mathrm{~m}$ tall guyed mast of a lattice, $2.6 \mathrm{~m}$ wide triangular structure. It was designed and equipped exclusively for scientific purposes according to recommendations by ICOS, ACTRIS (Aerosol, Clouds, and Trace Gases Research Infrastructure Network) and GMOS (Global Mercury Observation System). Measurement data are or will be provided also to the InGOS (Integrated non$\mathrm{CO}_{2}$ Greenhouse gas Observing System), EMEP (European Monitoring and Evaluation Programme), GAW (Global Atmosphere Watch) and ISKO (Czech Air Quality Information System) databases. The AS was built during 2012-2013 at $100 \mathrm{~m}$ distance from the Košetice Observatory, an infras- 
Table 1. Basic set of parameters measured at the Atmospheric Station Křešín u Pacova.

\begin{tabular}{|c|c|c|c|c|}
\hline Parameter & Instrument & $\begin{array}{l}\text { Time } \\
\text { step }\end{array}$ & Height (m) & Start \\
\hline $\mathrm{CO}_{2}, \mathrm{CH}_{4}$ & Picarro G2301 & $1 \mathrm{~h}$ & $10,50,125,250$ & Jan 2015 \\
\hline $\mathrm{CO}, \mathrm{N}_{2} \mathrm{O}$ & LGR $\mathrm{N}_{2} \mathrm{O} / \mathrm{CO}-23 \mathrm{~d}$ & $1 \mathrm{~h}$ & $10,50,125,250$ & Jan 2015 \\
\hline $\begin{array}{l}{ }^{13} \mathrm{C} \text { and }{ }^{18} \mathrm{O} \text { in } \mathrm{CO}_{2}, \\
\mathrm{H}_{2}, \mathrm{~N}_{2} \mathrm{O}, \mathrm{SF}_{6}, \mathrm{O}_{2} / \mathrm{N}_{2}\end{array}$ & Flask sampling & 1 week & 250 & 2015 \\
\hline $\mathrm{CO}_{2}, \mathrm{CH}_{4}, \mathrm{CO}, \mathrm{N}_{2} \mathrm{O}$ & Flask sampling & 1 week & 250 & 2015 \\
\hline${ }^{222} \mathrm{Rn}$ & To be decided & $\begin{array}{l}\text { To be } \\
\text { decided }\end{array}$ & 250 & $2015 / 2016$ \\
\hline${ }^{14} \mathrm{C}$ in $\mathrm{CO}_{2}$ & $\mathrm{NaOH}$ sorption flask & 1 week & 250 & 2015 \\
\hline $\mathrm{O}_{3}$ & Thermo 49i & $1 \mathrm{~min}$ & 10 or $50,125,230$ & Sep 2013 \\
\hline $\begin{array}{l}\text { Gaseous elemental } \\
\text { mercury }\end{array}$ & TEKRAN 2537B & $5 \mathrm{~min}$ & Ground, 240 & Dec 2012 \\
\hline $\begin{array}{l}\text { Elemental and organic } \\
\text { carbon }\end{array}$ & $\begin{array}{l}\text { Sunset Lab. Model-4 } \\
\text { Semi-Continuous } \\
\text { Field Analyzer }\end{array}$ & $4 \mathrm{~h}$ & Ground & Mar 2013 \\
\hline $\begin{array}{l}\text { Aerosol light } \\
\text { absorption }\end{array}$ & $\begin{array}{l}\text { Aethalometer Magee } \\
\text { Scientific AE31 }\end{array}$ & $5 \min$ & Ground & Sep 2012 \\
\hline $\begin{array}{l}\text { Aerosol light } \\
\text { scattering }\end{array}$ & $\begin{array}{l}\text { Nephelometer } \\
\text { TSI } 3563\end{array}$ & $1 \mathrm{~min}$ & Ground & Sep 2012 \\
\hline $\begin{array}{l}\text { Wind speed and } \\
\text { direction }\end{array}$ & $\begin{array}{l}\text { 2-D anemometer } \\
\text { WindObserver } 65\end{array}$ & $1 \mathrm{~min}$ & $\begin{array}{l}10,50,125,240, \\
250\end{array}$ & $\begin{array}{l}\text { May/Jul } \\
2014\end{array}$ \\
\hline Air pressure & $\begin{array}{l}\text { Barometer R. M. } \\
\text { Young } 61302\end{array}$ & $1 \mathrm{~min}$ & $\begin{array}{l}10,50,125,240, \\
250\end{array}$ & May 2014 \\
\hline $\begin{array}{l}\text { Air temperature and } \\
\text { relative humidity }\end{array}$ & Vaisala HMP155 & $1 \mathrm{~min}$ & $\begin{array}{l}10,50,125,240, \\
250\end{array}$ & May 2014 \\
\hline $\begin{array}{l}\text { Planetary boundary } \\
\text { layer height }\end{array}$ & $\begin{array}{l}\text { Ceilometer Vaisala } \\
\text { CL51 }\end{array}$ & $16 \mathrm{~s}$ & Estimate $3 \mathrm{~km}$ & Dec 2014 \\
\hline
\end{tabular}

tructure specialized in air quality and hydrological monitoring since 1988. The character of the site as a rural background station located in densely populated central Europe, far $(>80 \mathrm{~km})$ from major pollution sources (cities, industry), has been confirmed in numerous studies using air quality data from the Košetice Observatory (e.g. Dvorská et al., 2012; Zíková and Ždímal, 2013). Atmospheric long-range transport is expected especially from the west and northwest, comprising also marine air masses as calculated for the Košetice $\mathrm{Ob}$ servatory (Dvorská et al., 2009). The aim of this short paper is an introduction to this new multidisciplinary research infrastructure and presentation of the results of pilot studies based on two particular datasets measured at the AS.

\section{Methods}

\subsection{Measurements}

The AS is primarily designed to become an ICOS Level 1 station (required measurements are listed in the first six rows in Table 1). To fully exploit the infrastructure potential, selected air quality parameters were added to the list of measurement parameters (Table 1). Further long-term or campaign measurements may be added in future (e.g. halocarbons, isotopes in non- $\mathrm{CO}_{2} \mathrm{GHGs}$ ). Air quality and GHG monitoring is accompanied by meteorological measurements in order to support the interpretation of vertical and temporal concentration variabilities.

Air samples for GHG determination are transported in permanently flushed lines from different tower heights (Table 1) to analyzers placed in an air-conditioned ground based con- 
tainer. On the contrary, ozone and mercury analyzers are placed directly on the tower in an air-conditioned container installed at $230 \mathrm{~m}$ height directly on the mast body and in airconditioned racks placed on platforms at 10,50 and $125 \mathrm{~m}$ heights. This is because a long inlet system and analyzer on the ground may lead to large sample losses for these species (Galbally and Schultz, 2013). Aerosol instruments are placed in the ground-based container. Meteorological sensors are installed on $3 \mathrm{~m}$ long arms directed approximately south west (azimuth $215^{\circ}$ ) which is the windward side of the prevailing air flow. To cover the eastern flow an installation of additional arms directed north east (azimuth $35^{\circ}$ ) is planned.

\subsection{Pilot studies}

Two pilot studies were conducted on two selected datasets. Organic and elemental carbon (OC and EC, respectively), as important climate change drivers (Penner et al., 1998), were measured from August to December 2013 by a field semionline OC/EC analyser (Sunset Laboratory Inc., USA) using a $\mathrm{PM}_{2.5}$ cyclone inlet and a carbon parallel-plate diffusion denuder. Samples were taken at four-hour intervals, including the thermal-optical analysis, which lasts about $15 \mathrm{~min}$. This is a much higher time resolution in comparison with commonly used $24 \mathrm{~h}$ sampling. The analysis was performed using the shortened EUSAAR2 protocol (Cavalli et al., 2010; Vodička et al., 2013). Data quality is ensured using an internal standard $\left(\mathrm{CH}_{4}\right)$ during each analysis and by regular external calibration by sucrose solution.

EC data was used to investigate the occurrence of censored observations at the site, i.e. measurements under instrumental limits of detection and quantification (0.2 and $0.5 \mu \mathrm{gC} \mathrm{m}{ }^{-3}$, respectively). Censored data may occur often at background sites and they have to be handled carefully in order not to negatively influence monitoring results (Helsel, 2006). Since two fixed detection and quantification limits exist, it is necessary to work with type I doubly left-censored samples (e.g. Fusek and Michálek, 2013, 2014a). For statistical modeling of EC concentrations, the method of maximum likelihood was used. The Weibull distribution was selected as a model distribution because of its flexibility. Moreover, using the asymptotic properties of maximum likelihood estimates, asymptotic tests with nuisance parameters (Fusek and Michálek, 2014b) were applied for comparison of two censored samples.

One minute averages (mean of 4 values, reading every $15 \mathrm{~s}$ ) of temperature measured by the Vaisala HMP155 instrument at $10,50,125$ and $240 \mathrm{~m}$ in the period 11 June10 September 2014 (summer season) were investigated. Only those data were selected when records for all 4 measurement levels were available ( $92 \%$ of the whole period length). Vertical temperature gradients $-(\Delta T / \Delta z)$ were then calculated from the finite differences for the layers 10-50, 50-125 and $125-240 \mathrm{~m}$, and the data classified according to the gradient in the layer $10-50 \mathrm{~m}$. For convenient plotting of the shapes of vertical profiles including uncertainties, differences of the temperature at 50,125 and $240 \mathrm{~m}$ from the temperature at $10 \mathrm{~m}$ were also calculated.

\section{Results and discussion}

\subsection{Elemental and organic carbon}

$\mathrm{EC}$ and $\mathrm{OC}$ concentrations are slightly higher in autumn and winter 2013 (average of 0.76 and $0.70 \mu \mathrm{gC} \mathrm{m}^{-3}$ for $\mathrm{EC}$, respectively and 2.93 and $2.86 \mu \mathrm{gC} \mathrm{m}^{-3}$ for $\mathrm{OC}$, respectively) compared to summer 2013 (average of $0.39 \mu \mathrm{gC} \mathrm{m}^{-3}$ for EC and $2.33 \mu \mathrm{gC} \mathrm{m}^{-3}$ for OC). The results are similar to data obtained at the rural background site in Melpitz, Germany (Spindler et al., 2013) but lower in comparison with data from Diabla Góra, Poland (Rogula-Kozlowska et al., 2014). The time series of OC, EC, and EC/TC (where TC (total carbon) is the sum of EC and OC) are depicted in Fig. 1. The high variability of $\mathrm{OC}$ and $\mathrm{EC}$ concentrations is caused mainly by large changes in atmospheric mixing both due to variable boundary layer height and wind speed. A higher EC/TC ratio in autumn and winter usually indicates a higher proportion of combustion related sources (coal combustion and especially traffic, Lonati et al., 2005) and a lower proportion of secondary organic or primary biogenic aerosols among the EC and OC sources. Wood combustion emissions exhibit usually low EC/TC ratios (Hays et al., 2005).

The statistical methods based on censored samples were used for the analysis of EC measurements which contain a significant number of censored observations. A good example is the week of 21-27 October 2013, which contained approximately $25 \%$ of concentration data lower than or equal to $0.5 \mu \mathrm{gC} \mathrm{m}^{-3}$ (limit of quantification). The suitability of doubly left-censored Weibull distribution for modelling and comparison of EC concentrations was verified using Pearson's $\chi^{2}$ goodness-of-fit test. The null hypothesis was not rejected at a significance level of 0.05 with a $p$ value of 0.5445 . The investigation of daily, weekly and seasonal variability of EC concentrations is planned in future.

\subsection{Temperature}

Medians of the vertical temperature gradient in three layers (Fig. 2) reveal a typical summer daily course (Stull, 1988) although the plot is created from the whole summer dataset covering all weather conditions. Surface inversions dominate during nighttime, whereas the daytime is characterized by a convective boundary layer (CBL) with unstable stratification in the lower layer $(10-50 \mathrm{~m})$ and near-neutral stratification above. The lower layer has the largest diurnal amplitude of the temperature gradient, which crosses the adiabatic value early in the morning (preceded by the inversion destruction in this layer), reaches its maximum in the late morning, and again crosses the adiabatic value in the late afternoon. 


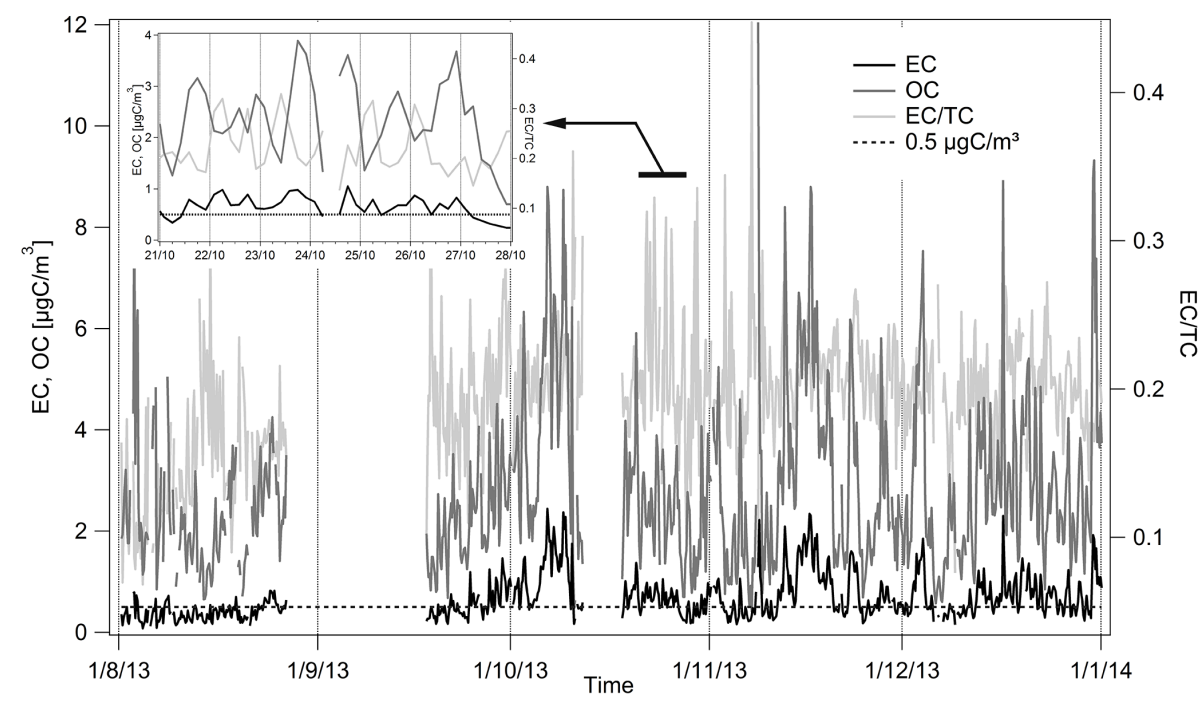

Figure 1. Time series of organic carbon (OC), elemental carbon (EC) and the ratio EC/TC where total carbon (TC) is sum of OC and EC. The limit of quantification for EC is depicted as a dashed line. The example time series for statistical investigation of censored observations is depicted in the small window.

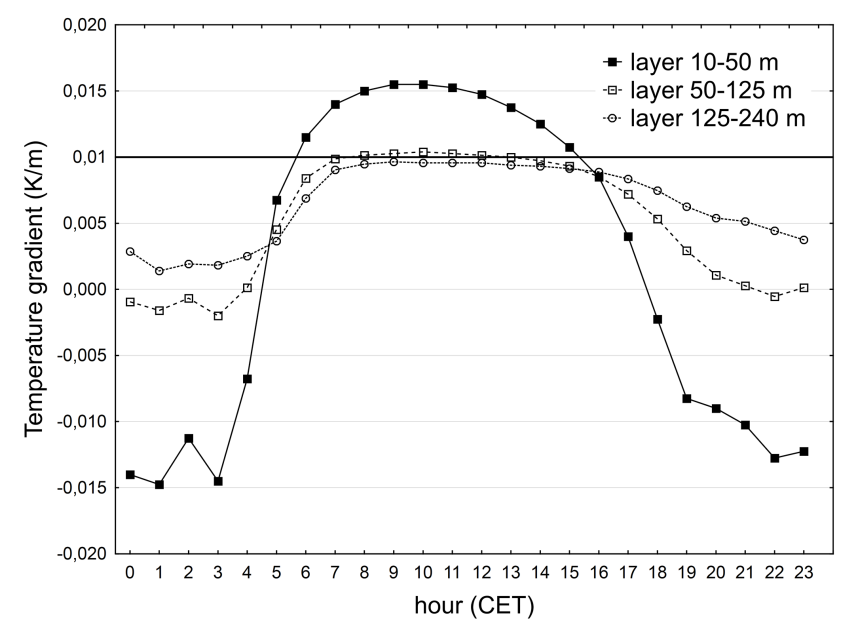

Figure 2. Daily course of summer medians of bulk vertical temperature gradient across three layers.

An example of the vertical temperature profile is given in Fig. 3 for the class of significant surface inversions (between -0.05 and $-0.015 \mathrm{~K} \mathrm{~m}^{-1}$ ) in the lowest layer. While the variability at $50 \mathrm{~m}$ is limited by the class definition, it increases with increasing height, reflecting different inversion depths and strengths. Relatively coarse vertical resolution and larger variability of the 1 min averages must also be kept in mind when analyzing the plot. In general, the medians in Fig. 3 suggest that in summer the tower top at $250 \mathrm{~m}$ is frequently above the nocturnal surface inversion, thus being decoupled from local influences.

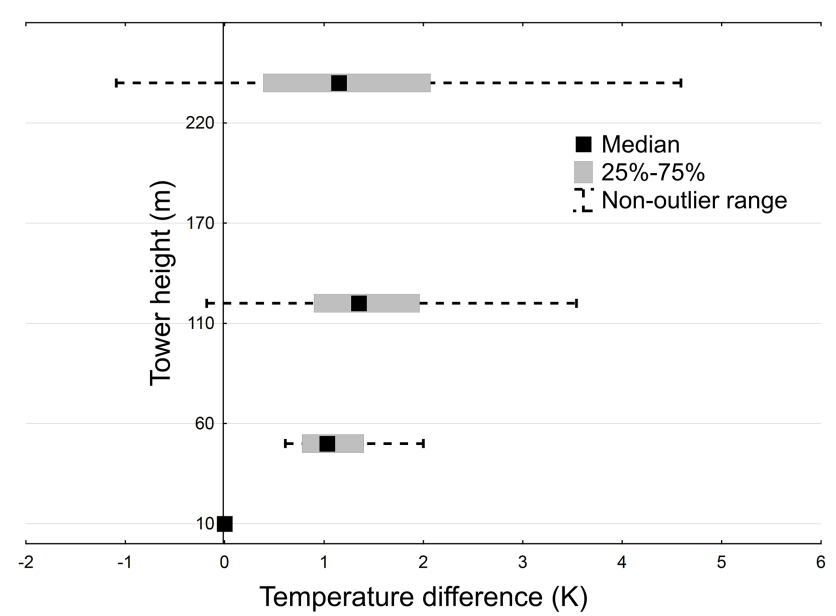

Figure 3. Vertical temperature profile for the stability class of significant surface inversions (between -0.05 and $-0.015 \mathrm{~K} \mathrm{~m}^{-1}$ of the temperature gradient in the layer $10-50 \mathrm{~m}$ ) in summer. Differences from the temperature at $10 \mathrm{~m}$ are plotted.

\section{Conclusions}

More pilot studies than presented here have to be conducted before regular monitoring and data interpretation can be started. General quality assurance, quality control and data validation procedures defined for monitoring programmes (e.g. Galbally and Schultz, 2013) have to be adjusted to the AS Křešín u Pacova particular conditions. Also, a tall tower concentration footprint (Vesala et al., 2008) for all sampling heights has to be calculated. Dynamics of the plantery boundary layer at the site and vertical gradients of meteorological 
parameters have to be studied. All this is currently under investigation.

Together with the adjacent Košetice Observatory, the AS forms the Colocated Station Košetice - Křešín u Pacova. Its manifold research infrastructure supports and claims for a multidisciplinary research approach. An important feature is also the combination of measurements for several atmospheric programs including GHGs, aerosols and gaseous pollutants with accompanying meteorological measurements. This preludes the monitoring supersites envisioned in the coming years. The AS Křešín u Pacova is an open access research infrastructure, proposals for collaborations are welcome.

Acknowledgements. This work was supported by the Ministry of Education, Youth and Sports of the Czech Republic within the National Sustainability Program I (NPU I), grant number LO1415.

Edited by: F. Beyrich

Reviewed by: J. Keder and M. Schumacher

\section{References}

Bakwin, P. S., Tans, P. P., Hurst, D. F., and Zhao, C. L.: Measurements of carbon dioxide on very tall towers: results of the NOAA/CMDL program, Tellus , 50, 401-415, 1998.

Cavalli, F., Viana, M., Yttri, K. E., Genberg, J., and Putaud, J.-P.: Toward a standardised thermal-optical protocol for measuring atmospheric organic and elemental carbon: the EUSAAR protocol, Atmos. Meas. Tech., 3, 79-89, doi:10.5194/amt-3-79-2010, 2010.

Dvorská, A., Lammel, G., and Holoubek, I.: Recent trends of persistent organic pollutants in air in central Europe - Air monitoring in combination with air mass trajectory statistics as a tool to study the effectivity of regional chemical policy, Atmos. Environ., 43, 1280-1287, 2009.

Dvorská, A., Komprdová, K., Lammel, G., Klánová, J., and Plachá, H.: Polycyclic aromatic hydrocarbons in background air in central Europe - seasonal levels and limitations for source apportionment, Atmos. Environ., 46, 147-154, 2012.

Fusek, M. and Michálek, J.: Statistical methods for analyzing musk compounds concentration based on doubly left-censored samples, Int. J. Math. Mod. Meth. Appl. Sci., 7, 755-763, 2013.

Fusek, M. and Michálek, J.: Statistical analysis of type I multiply left-censored samples from exponential distribution, J. Stat. Comput. Sim., 85, 2148-2163, doi:10.1080/00949655.2014.923886, 2014a.
Fusek, M and, Michálek, J.: Asymptotic tests for multiply leftcensored samples from Weibull distribution, edited by: Matousek, R., Proceedings of 20th International Conference on Soft Computing - MENDEL 2014, No. 20 in MENDEL, Brno, Czech Republic, 317-322, 2014b.

Galbally, E. and Schultz, M. G.: Guidelines for continuous measurements of ozone in the troposphere, GAW Report No. 209, WMO, Geneva, Switzerland, 2013.

Haszpra, L., Ramonet, M., Schmidt, M., Barcza, Z., Pátkai, Zs., Tarczay, K., Yver, C., Tarniewicz, J., and Ciais, P.: Variation of $\mathrm{CO}_{2}$ mole fraction in the lower free troposphere, in the boundary layer and at the surface, Atmos. Chem. Phys., 12, 8865-8875, doi:10.5194/acp-12-8865-2012, 2012.

Hays, M. D., Fine, P. M., Geron, C. D., Kleeman, M. J., and Gullett, B. K.: Open burning of agricultural biomass: Physical and chemical properties of particle-phase emissions, Atmos. Environ., 39, 6747-6764, 2005.

Helsel, D. R.: Fabricating data: How substituting values for nondetects can ruin results, and what can be done about it, Chemosphere, 65, 2434-2439, 2006.

Lonati, G., Giugliano, M., Butelli, P., Romele, L., and Tardivo, R.: Major chemical components of PM2.5 in Milan (Italy), Atmos. Environ., 39, 1925-1934, 2005.

Monna, W. and Bosveld, F.: In Higher Spheres: 40 Years of Observations at the Cabauw Site, KNMI Publication 232, KNMI, De Bilt, the Netherlands, 2013.

Penner, J. E., Chuang, C. C., and Grant, K.: Climate forcing by carbonaceous and sulfate aerosols, Clim. Dynam., 14, 839-851, 1998.

Rogula-Kozłowska, W., Klejnowski, K., Rogula-Kopiec, P., Ośródka, L., Krajny, E., Błaszczak, B., and Mathews, B.: Spatial and seasonal variability of the mass concentration and chemical composition of $\mathrm{PM}_{2.5}$ in Poland, Air Qual. Atmos. Health, 7, 41-58, 2014.

Spindler, G., Grüner, A., Müller, K., Schlimper, S., and Herrmann, H.: Long-term size-segregated particle $\left(\mathrm{PM}_{10}, \mathrm{PM}_{2.5}, \mathrm{PM}_{1}\right)$ characterization study at Melpitz - influence of air mass inflow, weather conditions and season, J. Atmos. Chem., 70, 165-195, 2013.

Stull, R. B.: An introduction to boundary layer meteorology, Kluwer Acad., Norwell, Mass., 1988.

Vesala, T., Kljun, N., Rannik, Ü., Rinne, J., Sogachev, A., Markkanen, T., Sabelfeld, K., Foken, T., and Leclerc, M. Y.: Flux and concentration footprint modelling: State of the art, Environ. Pollut., 152, 653-666, 2008.

Vodička, P., Schwarz, J., and Ždímal, V.: Analysis of one year's OC/EC data at a Prague suburban site with 2-h time resolution, Atmos. Environ., 77, 865-872, 2013.

Zíková, N. and Ždímal, V.: Long-term measurement of aerosol number size distributions at rural background station Košetice, Aerosol Air Qual. Res., 13, 1464-1474, 2013. 